\title{
INDICE GENERAL
}

Prólogo de la segunda edición..................... 7

Del Prólogo de la primera edición. .................... 9

1. Condicionamiento sociocultural de la idea del aprendizaje........ 11

2. El aprendizaje como objeto de investigación............. 14

3. Bosquejo provisional de las características generales del aprendizaje.. . 23

4. La primitiva investigación del aprendizaje: La memoria, la atención y la reproducción........................... 26

5. El aprendizaje, según la idea de la señal condicionante y la respuesta condicionada............................. 38

6. El aprendizaje por el éxito ..................... 46

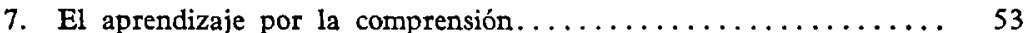

8. El aprendizaje y el móvil........................ 63

9. El aprendizaje en el asociacionismo conductista ............ 74

10. El aprendizaje y la conducta . . . . . . . . . . . . . . . . . 79

11. El aprendizaje de conducta demandada y of recida ........... 100

12. El aprendizaje y la conducta cognoscitiva............... 111

13. El aprendizaje de emociones y el alivio por la verbalización...... 120

14. La teoría bifactorial del aprendizaje................. 133

15. El aprendizaje como transformación de la probabilidad de relación de la selección de estímulos y la emisión de respuestas........ 148

16. La práctica................................. 159

17. La transferencia del aprendizaje y la generalización.......... 167

18. Comparar y distinguir: El aprendizaje de discernimiento....... 176

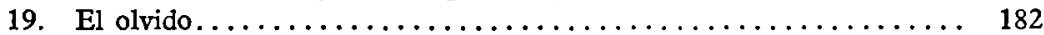

20. Capacidades de aprendizaje.................... 194

21. Biología y patología del aprendizaje................ 201

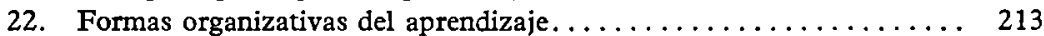

23. El aprendizaje y la comunicación................. 221

24. El aprendizaje en los sistemas de referencia semántica......... 233

25. Modelos cibernéticos del aprendizaje................. 249

26. El aprendizaje como acción e interacción............... 267

fndice de nombres........................... 283

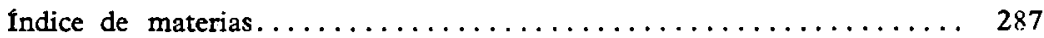




\title{
MONOGRAFías DE PSICOLOGÍA NORMAL Y PATOLÓGICA
}

\author{
publicadas bajo la dirección del \\ D R . J O S E G E R M A I N
}

\author{
SERIE AZUL \\ psicologí científica Y escuelas psicológicas
}

1. David Katz: PSicologia de la forma.

2. JoRANNES MÜLLER: LOS FENÓMENOS FANTÁSTICOS DE LA VISIÓN.

4. Jolande Jacobi: LA PSICOLOGfa dE C. G. JUNG.

5. E. D. Adrian: LA BASE DE LA SENSACIón.

\author{
SERIE VERDE \\ PSicología pedagógica - psicología industhial - tests psicológicos \\ ESTADística PSICOLÓgICA - PSICOLOGÍA SOCIAL
}

3. José Mallart: ORIENTACión FUNCIONAL Y FORMACión PRoFESIONAL.

7. Caleb Gattegno: introducción a la psicología de la AFECTIVIDAD Y A LA EDUCACIÓN PARA EL AMOR.

10. Donald E. Super, M. A. (Oxon), Рh. D., y John. O Crites, Ph. D.: LA MEDIDA DE LAS APTITUDES PROFESIONALES.

\author{
SERIE OCRE \\ PSICOLOGía médica - PSICOPATOLOGía
}

8. Ralph T. Collins: Manual de neURología y PSiQuiatría EN MEDICINA DEL TRABAJO.

9. Alfred farau y Herbert Shaffer: la psicología profunda.

11. José María López Piñero y José María Morales Meseguer: NEU. ROSIS Y PSICOTERAPIA.

12. Marc Oraison: EL AZAR Y LA VIDA.

\section{SERIE ENCARNADA}

PSICOLOGIA ANIMAL

6. DAvid Katz: ANIMALES Y HOMBRES. 